\title{
ATITUDES, SENTIMENTOS E IMAGENS NA REPRESENTAÇÃO SOCIAL DA SEXUALIDADE ENTRE ADOLESCENTES
}

\author{
Attitudes, feelings and images on the social representation \\ of sexuality among adolescents
}

\section{Actitudes, sentimientos e imágenes de la representación social de la sexualidad entre los adolescentes}

\author{
Denize Cristina de Oliveira ${ }^{1}$ \\ Ana Paula Munhen de Pontes
}

Antônio Marcos Tosoli Gomes ${ }^{2}$

Luiz Phillipi Porto Salgado ${ }^{4}$

\section{RESUMO}

Este trabalho tem como objetivo analisar a estrutura da representação social de sexualidade para adolescentes. De natureza qualitativa, foi desenvolvido com 746 jovens de duas escolas públicas do Rio de Janeiro. Os dados foram coletados por meio de evocações livres ao termo indutor "sexualidade" e analisados pelo software EVOC 2003. 0 conjunto dos sujeitos apresenta uma estrutura representacional positiva, englobando dimensões atitudinais, valorativas e imagéticas. Aspectos negativos aparecem na periferia, indicando uma dimensão familiar e de consequências. Comparando a estrutura das representações por sexo, observase que são semelhantes, especialmente pela presença de elementos como "bom", "camisinha" e "prevenção". A especificidade do grupo feminino aparece enfatizando a dimensão atitudinal, enquanto o masculino se distingue por uma associação da sexualidade ao ato sexual. Conclui-se que as representações estão ligadas a comportamentos adotados diante da sexualidade e da sua valorização, bem como da existência de dimensões transversais às diversas estruturas.

Palavras-chave: Sexualidade. Saúde do Adolescente. Pesquisa Qualitativa. Enfermagem

\begin{abstract}
This paper aims to analyze the structure of social representation of sexuality for adolescents. With a qualitative nature, was developed with 746 young people from two public schools in Rio de Janeiro. Data were collected through free evocations about the term inducer "sexuality" and analyzed by the software EVOC 2003. The set of subject presents a positive representational structure, including attitudinal dimensions, values and imagery. Negative aspects appear on the periphery showing a family dimension and consequences. Comparing the structure of representations by sex, it is observed that are similar, especially by the presence of elements as "good", "condom" and "prevention". The specificity of the female group appears emphasizing the attitudinal dimension, while the male group is distinguished by a combination of sexuality to the sexual act. We conclude that the representations are linked to behaviors adopted front of sexuality and its recovery as well as the existence of transversal dimensions to the various structures.
\end{abstract}

KeyWords: Sexuality. Adolescent Health. Qualitative Research. Nursing

\section{Resumen}

La presente investigación tiene como objetivo analizar la estructura de representación social de la sexualidad entre los adolescentes. Estudio de tipo cualitativo, desarrollado con 746 jóvenes de dos escuelas públicas de Río de Janeiro. Los datos fueron colectados por medio de evocaciones libres frente al inductor "sexualidad" y analizados por el software EVOC 2003. El grupo de sujetos estudiados presenta una estructura positiva de representación, incluyendo dimensiones de actitud, de valor y de imagen. Aspectos negativos aparecen en la periferia, lo que indica una escala relativa y las consecuencias. En la comparación de la estructura de las representaciones de género se observó que son similares, sobre todo por la presencia de elementos como "bueno", "condón" y "prevención". La especificidad de las mujeres en el grupo aparece haciendo énfasis en la dimensión de las actitudes, mientras que el masculino, se distingue por una asociación de sexualidad con el acto sexual. Llegamos a la conclusión de que las representaciones están ligadas a comportamientos adoptados frente a la sexualidad y a su valorización, así como a la existencia de dimensiones transversales a las diversas estructuras.

Palabras clave: Sexualidad. Salud del Adolescente. Investigación Cualitativa. Enfermería

\footnotetext{
${ }^{1}$ Professora Titular da Faculdade de Enfermagem da Universidade do Estado do Rio de Janeiro (FENF/UERJ). Brasil. E-mail: dcouerj@gmail.com, 2Professor Adjunto da FENF/UERJ. Doutor em Enfermagem pela Escola de Enfermagem Anna Nery/UFRJ (EEAN/UFRJ). Brasil. E-mail: mtosoli@gmail.com, ${ }^{3}$ Enfermeira - Mestranda do Programa de Pós-Graduação em Enfermagem da FENF/UERJ. Brasil. E-mail: anamunhen@gmail.com, ${ }^{4}$ Enfermeiro. $2^{0}$ tenente
} do Corpo de Bombeiros/RJ. Brasil. E-mail: fiupis@yahoo.com.br 


\section{INTRODUÇÃO}

A adolescência é um tema que vem ganhando grande valorização e relevância no contexto das problemáticas levantadas em estudos, tanto no campo da educação quanto da saúde. Este é um importante período do ciclo vital, visto que é nele que se desenvolve grande parte do processo de crescimento e desenvolvimento humano, em que se observa um acentuado amadurecimento corporal; significativas transformações emocionais; construção de novas relações interpessoais; manifestações de novos sentimentos; atitudes; decisões resultando na construção de uma identidade própria.

Na sociedade contemporânea torna-se cada vez mais comum o início da atividade sexual ainda na adolescência, e, muitas vezes, estes jovens não se encontram preparados para assumir tal responsabilidade, considerando a imaturidade ou inexperiência nestas questões, falta de acesso a informações, seja no ambiente escolar ou familiar, pelas características próprias desta fase da vida, dentre outras, o que pode resultar em gravidez não planejada, abortos inseguros e aumento dos índices de DST/AIDS neste grupo populacional.

A sexualidade é uma característica essencial do ser humano, presente em todas as etapas da vida, sendo manifestada de diversas formas. Envolve um conjunto de valores pessoais e sociais, além de práticas corporais, sendo uma forma de expressão que reflete o contexto sociocultural no qual o sujeito está inserido e se desenvolve, além de estar associada à atividade sexual, à dimensão biológica, íntima, relacional e subjetiva de cada indivíduo. ${ }^{1}$

Uma das dimensões que conformam o ser humano é, pois, a sexualidade, envolvendo o gênero, a orientação sexual, 0 erotismo, o envolvimento emocional, o amor e a reprodução. Esta é uma visão bem mais ampla do que a representação que diferentes grupos sociais possuem acerca deste evento. É experimentada nos pensamentos, nas fantasias, desejos, crenças, dentre vários outros, envolvendo o corpo, a história e a cultura. A vivência da sexualidade na adolescência participa da estruturação da identidade do jovem. ${ }^{2}$

A preocupação com a saúde sexual dos adolescentes tem atraído atenção especial de diversas áreas do conhecimento, dentre elas a enfermagem, despertando o interesse pela sua exploração, a partir de uma perspectiva da subjetividade social nela implicada. Desta forma, os objetivos deste estudo foram descrever os conteúdos e analisar comparativamente a estrutura das representações sociais de adolescentes acerca da sexualidade.

\section{METODOLOGIA}

Trata-se de um estudo descritivo com abordagem metodológica qualitativa, fundamentado na Teoria de Representações Sociais, conforme proposta por Moscovici ${ }^{3}$, em 1961, no âmbito da Psicologia Social. Será utilizada, ainda, uma abordagem teórica complementar, denominada Teoria do Núcleo Central ou Abordagem Estrutural das Representações Sociais. ${ }^{4 ; 5}$

A representação social é composta por um conjunto de informações, crenças, valores e atitudes acerca de um objeto social e pode ser organizada, estruturada e constituída num sistema sociocognitivo. ${ }^{6} \mathrm{~A}$ abordagem estrutural se ocupa do conteúdo cognitivo das representaç̃̃es e a concebe como um conjunto estruturado e não como uma simples coleção de ideias e valores. Sua principal contribuição está centrada na proposição de que o conteúdo da representação se organiza em um sistema central e em um sistema periférico, que possuem características e funções distintas. ${ }^{5} 0$ núcleo central é determinado pelo tipo e natureza do objeto representado, pelo tipo de relações que 0 grupo mantém com este objeto e pelo sistema de valores e normas sociais que constituem o ambiente ideológico do grupo. ${ }^{7}$

Os sujeitos estudados foram 746 adolescentes de duas escolas públicas do município do Rio de Janeiro, com idades compreendidas entre 14 e 22 anos, cursando entre a $1^{\mathrm{a}}$ e a $3^{\mathrm{a}}$ série do ensino médio. Para a definição da faixa etária, a adolescência foi considerada dentro de uma faixa mais ampla, que vai dos 12 aos 22 anos, de acordo com os conceitos de Thompson e Ashwill.'. A escolha destas duas escolas como cenário do estudo, obedeceu aos seguintes critérios de inclusão: ser de fácil acesso, de forma que comportasse uma diversidade de características sociais dos alunos; oferecer ensino médio; e contar com aulas nos períodos diurno e/ou noturno.

0 período de coleta de dados ocorreu de agosto a dezembro de 2003, a partir da aplicação de um instrumento de coleta de evocações livres, sendo utilizado como termo indutor a palavra "sexualidade". Foram realizadas sucessivas visitas às duas escolas, nos períodos diurno (manhã e tarde) e noturno.

Foi solicitado aos jovens que escrevessem cinco palavras que viessem imediatamente às suas mentes quando eles ouviam o termo indutor referido acima. 0 caráter espontâneo e a dimensão projetiva desta técnica permitem 0 acesso aos elementos que constituem o universo semântico do objeto estudado, com maior facilidade do que em uma entrevista. ${ }^{9 ; 5}$

Para a análise dos dados coletados foi utilizado o software EVOC 2003, que organiza os termos produzidos em função da hierarquia subjacente à frequência e à ordem de evocaçãa ${ }^{4 ; 5 ; 10}$. 0 EVOC permite identificar os elementos pertencentes, ao provável núcleo central da representação, bem como os elementos periféricos, a partir de dois critérios: a frequência média de ocorrência das palavras e o grau de importância atribuído a elas, por meio do lugar ocupado na ordem de evocação. Os dados foram analisados a partir de sua distribuição no quadro de quatro casas, ${ }^{4 ; 0}$ construído a partir do cruzamento dos dois critérios referidos; as palavras mais frequentes e mais prontamente evocadas se localizam no núcleo central, e as palavras menos prontamente evocadas se localizam na periferia da representação. 
Foram respeitadas as normas e os aspectos éticos de acordo com a Resolução no.196/1996 do Conselho Nacional de Saúde. A pesquisa foi encaminhada e aprovada pelo Comitê de Ética em Pesquisa da Universidade do Estado do Rio de Janeiro, sob protocolo nº 002/2004, ano 2004. Após a aprovação do CEP, foi solicitada autorização institucional à direção das duas escolas. No momento da coleta de dados, foram expostos os objetivos do estudo aos sujeitos e explicados todos os direitos

\section{APRESENTAÇÃO E DISCUSSÃO DOS RESUL-} TADOS que eles tinham como consequência da legislação ética em pesquisa existente no Brasil, inclusive a manutenção da participação voluntária e o direito de renunciar à sua inclusão em seu desenvolvimento, mesmo após a sua colaboração. $\mathrm{Na}$ sequência, foi apresentado o termo de consentimento livre e esclarecido para cada adolescente participante do estudo e solicitado que 0 assinasse, autorizando sua par ticipação na pesquisa.

Como mencionado anteriormente, foram entrevistados 746 adolescentes, que evocaram um total de 2.956 palavras associadas ao termo sexualidade, e destas, 253 eram diferentes.

Figura 1 - Análise das Evocações ao termo indutor "Sexualidade". Rio de Janeiro, 2007. ( $\mathrm{n}=746$ sujeitos)

\begin{tabular}{|c|c|c|c|c|c|c|}
\hline O.M.E. & \multicolumn{3}{|l|}{$<2,6$} & \multicolumn{3}{|l|}{$\geq 2,6$} \\
\hline $\begin{array}{l}\text { Freq. } \\
\text { Média }\end{array}$ & Termo evocado & Freq. & O.M.E & Termo evocado & Freq. & O.M.E \\
\hline$\geq 95$ & $\begin{array}{c}\text { Responsabilidade } \\
\text { Bom } \\
\text { Camisinha } \\
\text { Transar }\end{array}$ & $\begin{array}{l}185 \\
156 \\
116 \\
111\end{array}$ & $\begin{array}{l}2,52 \\
2,15 \\
2,50 \\
2,03\end{array}$ & $\begin{array}{l}\text { Prevenção } \\
\text { Prazer } \\
\text { Amor }\end{array}$ & $\begin{array}{l}171 \\
163 \\
155\end{array}$ & $\begin{array}{l}2,60 \\
2,62 \\
2,83\end{array}$ \\
\hline$<75$ & $\begin{array}{c}\text { Necessário } \\
\text { Gênero } \\
\text { Maravilhoso } \\
\text { Normal } \\
\text { Cuidado } \\
\text { Opção } \\
\end{array}$ & $\begin{array}{l}90 \\
70 \\
63 \\
62 \\
59 \\
38 \\
\end{array}$ & $\begin{array}{l}2,33 \\
2,24 \\
2,31 \\
2,08 \\
2,42 \\
2,47 \\
\end{array}$ & $\begin{array}{l}\text { Respeito } \\
\text { Doenças } \\
\text { Filhos } \\
\text { Saudável } \\
\text { Consciência }\end{array}$ & $\begin{array}{l}89 \\
59 \\
52 \\
41 \\
40\end{array}$ & $\begin{array}{l}2,84 \\
3,28 \\
2,96 \\
2,68 \\
2,80\end{array}$ \\
\hline
\end{tabular}

A Figura 1 mostra a distribuição das palavras evocadas formando o "quadro de quatro casas", como proposto por Sá4 e Oliveira. ${ }^{10}$ No quadrante superior esquerdo, possível núcleo central da representação dos adolescentes sobre sexualidade, encontram-se as seguintes palavras: responsabilidade, bom, camisinha e transar. Estas se assemelham por serem as palavras mais evocadas por estes jovens e, também, as mais prontamente evocadas. Estes termos apresentam frequências superiores a 95 e, ao mesmo tempo, obtiveram médias de evocações inferiores a 2,6, sendo as mais prontamente evocadas.

Toda representação se organiza em torno de um núcleo central, que é o elemento fundamental da representação. 0 núcleo central é um subconjunto da representação, cuja ausência daria uma significação radicalmente diferente à representação em seu conjunto, por outro lado, é o elemento mais estável da representação. ${ }^{6}$ Uma representação é suscetível de variar por uma mudança no sentido ou na natureza dos seus elementos periféricos. Mas ela só se transforma quando o núcleo central é posto em questão. ${ }^{5 ; 7}$

0 conjunto dos sujeitos apresenta uma estrutura representacional positiva associada à sexualidade, englobando dimensões atitudinais (responsabilidade e camisinha), valorativas (bom) e imagéticas e comportamentais (transar). Uma característica relevante do suposto núcleo central é a associação, por parte desses jovens, da sexualidade com o ato sexual. Assim, é possível perceber que uma diferenciação ampliada dos significados de sexualidade e prática sexual ainda não foi incorporada pelos adolescentes.

Assim, destaca-se que a sexualidade 2:29

é uma das dimensões do ser humano que envolve gênero, identidade sexual, orientação sexual, erotismo, envolvimento emocional, amor e reprodução. É experimentada ou expressa em pensamentos, fantasias, desejos, crenças, atitudes, valores, atividades, práticas, papéis e relacionamentos... Assim, é a própria vida. Envolve, além do nosso corpo, nossa história, nossos costumes, nossas relações afetivas, nossa cultura.

A presença de palavras como transar e bom revelam a aproximação da sexualidade com o ato sexual, ou seja, a representação do real significado de sexualidade para estes jovens, e também, a valorização da atividade sexual.

Este significado pode estar atrelado à exposição, cada vez mais frequente na mídia, da sexualidade associada a relações sexuais, por meio de campanhas preventivas para DSTs. Neste contexto, destaca-se que as representações atuam como guia 
para as práticas, bem como para as ações e as relações sociais; ${ }^{6}$ por isso, pode-se afirmar que os adolescentes têm comportamentos voltados para as práticas sexuais na vivência da sexualidade.

Outro ponto que chama atenção é a presença dos termos camisinha e responsabilidade no núcleo central, sugerindo que houve um processo de incorporação dos conhecimentos relativos à prevenção em saúde reprodutiva, revelando possivelmente 0 sucesso das campanhas de educação em saúde.

Vale ainda ressaltar que a palavra responsabilidade foi a mais evocada, e a palavra transar foi a mais prontamente evocada, tornando possível perceber que as campanhas em massa veiculadas na mídia, na internet, na escola e nos centros de saúde, que orientam quanto à prática de uma atividade sexual segura, podem estar atingindo os jovens. No entanto, é possível observar em diversos estudos a existência de conflitos entre representações e práticas, pois, apesar de conhecerem os métodos preventivos, muitos jovens ainda não fazem uso deles, ou seja, ainda não o incorporaram em suas práticas. 2;11;12 Este fato pode ser constatado pelo aumento gradativo dos índices de doenças sexualmente transmissíveis e da própria gravidez na adolescência.

0 termo responsabilidade merece destaque, pois como já foi dito anteriormente, foi a palavra mais evocada por este grupo. Isso remete à vivência de uma sexualidade responsável, com adoção de métodos preventivos. Neste sentido, destacase a existência de conhecimento entre os adolescentes com relação às medidas de prevenção envolvidas na atividade sexual; entretanto, esse conteúdo representacional não pode ser associado à efetiva adoção de práticas preventivas, mas apenas ao seu conhecimento.

Os elementos que se encontram no quadrante superior direito são denominados primeira periferia. Neste quadrante encontram-se termos como prevenção, prazer e amor. Tornase importante ressaltar que a palavra prevenção, estatisticamente, está praticamente dentro do núcleo central, reforçando as noções de responsabilidade e cuidado, que é outro termo presente entre os elementos periféricos.

A associação das palavras prazer e amor remete a um conteúdo também intimamente ligado ao ato sexual, porém com um referencial que denota uma mudança no comportamento habitual dos jovens quanto ao enfoque do ato em si, trazendo a ideia de uma ressignificação desta prática, relacionada com o amor, sem abrir mão do prazer.

0 léxico prazerfoi evocado com quantitativo importante, além de uma ordem média de evocação muito próxima do núcleo central, chamando a atenção para a importância que os jovens atribuem às suas relações sexuais em que, de forma sugestiva, prioriza a qualidade em detrimento da quantidade.

Mesmo nos dias atuais, muitas mulheres associam a prática sexual ao amor, principalmente na sua iniciação, uma vez que atualmente ainda existem dispositivos de controle que agem no plano simbólico e criam espaços de tensão na decisão dos jovens em dar início à vida sexual. ${ }^{2}$

A evocação dos termos necessário, maravilhoso o opção trazem consigo a ideia de satisfação associada à atividade sexual, mostrando a importância da sexualidade na vida dos jovens, como sendo algo necessário e bom. Merece destaque a importância do termo opção, que pode ser caracterizado por diversos significados, como: opção sobre quando e com quem iniciar a vida sexual; e opção de liberdade para escolher se relacionar livremente com o parceiro do mesmo sexo ou do sexo oposto.

Além destes elementos, foi possível observar a presença do léxico gênero, que discrimina a constituição de representações da sexualidade, dentre outras coisas, por papéis sociais. Assim, alguns adultos que são referências, como os pais, colaboram para reprodução da ideologia de gênero veiculada na sociedade, considerando que homens e mulheres podem lidar diferentemente com apelos da libido, e que as mulheres naturalmente devem dominar o desejo sexual.

Neste sentido, historicamente, a sociedade estabeleceu uma subordinação das mulheres com relação à sexualidade e, por isso, ainda existe um preconceito no que diz respeito ao início das atividades sexuais para elas ${ }^{13}$, caracterizando diferenças de gênero que ainda são marcantes em nossa sociedade.

Complementar a essa visão, destaca-se a presença do léxico normal, que remete à ideia de obrigatoriedade de uma atividade sexual mais precoce e intensa por parte do sexo masculino, a fim de se diferenciar do feminino e ser considerado adulto. Assim, não basta ter se iniciado sexualmente cedo, mas importa também a frequência da atividade sexual e a sua "naturalização".

Os elementos presentes no quadrante inferior direito configuram a segunda periferia e sugerem a presença de uma dimensão de consequências negativas que não estão tão firmadas nas representações desses elementos, motivo pelo qual vocábulos como respeito, doenças e filhos estão nesta localização. Ao mesmo tempo, refletem uma aproximação com o cotidiano e um contato com as práticas desenvolvidas pelos jovens.

Este fato reforça os resultados encontrados em outros estudos, que demonstram uma divergência entre conhecimentos e práticas. A presença das palavras doenças e filhos na periferia da representação demonstra uma integração com as experiência cotidianas vividas pelos jovens.

Neste sentido, o aumento gradativo da gravidez na adolescência e a presença cada vez mais constante de DSTs/ AIDS entre os adolescentes são fatores que contribuem para esta configuração do sistema periférico. Este sistema permite a integração das experiências e das histórias individuais dos atores sociais, apresenta-se sensível ao contexto social imediato, mas também se mostra flexível, permitindo adaptação à realidade. ${ }^{6}$ Assim, pode-se dizer que o sistema periférico favorece a conexão entre a representação da sexualidade e as condições práticas e cotidianas que a envolvem.

Ao observar a estrutura representacional no seu conjunto, é possível associar o termo sexualidade a diversas categorias: 
sexualidade associada à responsabilidade; à satisfação; e ao próprio ato sexual. Os termos, responsabilidade, camisinha, cuidado, prevenção, consciência e respeito parecem estar associados a uma atitude responsável. Já os termos, bom, prazer, opção, amor e maravilhoso associam-se à satisfação, enquanto que as palavras, transar, gênero, necessário, normal, doenças, filhos e saudável estão ligadas ao ato sexual em si e a sua expressão comportamental.

Os termos bom, camisinha e transar, que compõem o possível núcleo central da representação, e os termos doença, filho e saudável, que aparecem na periferia, apresentam significados relacionados à prática sexual dos adolescentes, enquanto termos como responsabilidade, presente no núcleo central, e respeito e consciência, que aparecem como periféricos, remetem a significados que se relacionam com uma atitude responsável por parte destes jovens. Desta forma, pode-se afirmar que a representação social do grupo estudado sobre a sexualidade é sustentada por meio das dimensões de responsabilidade e da prática sexual.

Sendo a questão de gênero muito marcante em nossa sociedade, e especialmente nas questões da sexualidade, procedeu-se à comparação da representação para adolescentes do sexo feminino e do sexo masculino, como se pode observar nas Figuras 2 e 3.

Figura 2: Análise das Evocações do sexo feminino sobre o termo indutor "Sexualidade". Rio de Janeiro, 2007. ( $n=436$ sujeitos)

\begin{tabular}{|c|c|c|c|c|c|c|}
\hline O.M.E. & $<2,7$ & & & $\geq 2,7$ & & \\
\hline Freq. Media & Termo evocado & Freq. & P.M.E & Termo evocado & Freq. & O.M.E \\
\hline$\geq 52$ & $\begin{array}{c}\text { Responsabilidade } \\
\text { Prevenção } \\
\text { Prazer } \\
\text { Camisinha } \\
\text { Bom }\end{array}$ & $\begin{array}{r}139 \\
108 \\
102 \\
70 \\
69\end{array}$ & $\begin{array}{l}2,38 \\
2,66 \\
2,57 \\
2,41 \\
1,94\end{array}$ & $\begin{array}{c}\text { Amor } \\
\text { Respeito }\end{array}$ & $\begin{array}{r}100 \\
60\end{array}$ & $\begin{array}{l}2,81 \\
3,08\end{array}$ \\
\hline$<52$ & $\begin{array}{l}\text { Necessário } \\
\text { Transar } \\
\text { Cuidado } \\
\text { Normal } \\
\text { Maravilhoso } \\
\text { Gênero } \\
\text { Saudável } \\
\text { Opção } \\
\text { Tempo certo }\end{array}$ & $\begin{array}{l}49 \\
47 \\
40 \\
38 \\
32 \\
27 \\
23 \\
21 \\
19\end{array}$ & $\begin{array}{l}2,38 \\
2,12 \\
2,35 \\
1,92 \\
1,90 \\
2,18 \\
2,69 \\
2,19 \\
2,00\end{array}$ & $\begin{array}{l}\text { Doenças } \\
\text { Amadurecimento } \\
\text { Consciência } \\
\text { Carinho } \\
\text { Filhos }\end{array}$ & $\begin{array}{l}36 \\
32 \\
30 \\
27 \\
24\end{array}$ & $\begin{array}{l}3,38 \\
2,84 \\
2,73 \\
3,07 \\
3,20\end{array}$ \\
\hline
\end{tabular}

Figura 3: Análise das Evocações do sexo masculino sobre o Termo indutor "Sexualidade". Rio de Janeiro, 2007. ( $n=310$ sujeitos)

\begin{tabular}{|l|c|l|l|l|r|r|}
\hline O.M.E. & \multicolumn{2}{|l|}{ <,7 } & \multicolumn{2}{|c|}{$\geq 2,7$} & \multicolumn{2}{|c|}{} \\
\hline Freq. & Termo evocado & Freq. & O.M.E & Termo evocado & Freq. & O.M.E \\
Med. & Bom & 87 & 2,32 & & & \\
\multirow{4}{*}{$\geq 44$} & Transar & 64 & 1,96 & Prazer & 61 & 2,70 \\
& Prevenção & 63 & 2,49 & Amor & 55 & 2,89 \\
& Camisinha & 46 & 2,63 & Responsabilidade & 46 & 2,93 \\
\hline \multirow{4}{*}{$<4$} & Gênero & 43 & 2,27 & Maravilhoso & 31 & 2,74 \\
& Necessário & 41 & 2,26 & Filhos & 28 & 2,75 \\
& Respeito & 29 & 2,34 & Doenças & 23 & 3,13 \\
& Normal & 24 & 2,33 & Fantasias & 20 & 3,50 \\
\hline
\end{tabular}

Ao comparar as Figuras 2 e 3, que dizem respeito às evocações dos adolescentes dos sexos feminino e masculino, observa-se que os seus elementos são semelhantes, especialmente pela presença de elementos comuns como bom, camisinha e prevenção. Um elemento que merece destaque é o conteúdo positivo característico da representação dos dois grupos, presentes também nos núcleos centrais.

Em ambos os núcleos centrais, que expressam o que há de mais duradouro na representação, os vocábulos presentes sugerem uma importante dimensão de responsabilidade associada à sexualidade, já que, para os dois grupos, o ato sexual é visto como uma coisa boa e a prevenção não está dissociada desse ato no mapa cognitivo dos jovens.

No entanto, a especificidade do grupo feminino aparece na palavra responsabilidade, enfatizando uma dimensão atitudinal por parte das jovens, enquanto o masculino se distingue por uma associação da sexualidade ao ato sexual, através do léxico transar. Estes achados são bastante significativos, pois caracterizam diferenças de gênero, que são vivenciadas e tão firmemente impregnadas em nossa cultura. 
Um fenômeno que sofre influência deste processo é o da iniciação sexual. Durante este percurso se dá a afirmação da masculinidade, que determina pensamentos e ações, moldagens sobre a feminilidade e a busca por autonomia, 0 que no senso comum se traduz como tornar-se homem e fazerse mulher, perpassando, portanto, sentidos e identidades múltiplas, como o que se entende por masculino e feminino.

As transformaç̃os ocorridas no comportamento sexual das mulheres, decorrentes do movimento feminista dos anos 60, contribuíram para a emancipação sexual feminina, e a mulher passou a ter uma visão ampliada de sua sexualidade. No entanto, percebe-se que, apesar destas alterações no comportamento feminino, velhos padrões ainda fazem parte da educação dos adolescentes. ${ }^{14}$ Assim, os homens assumem papéis muitas vezes machistas e as algumas mulheres ainda se apresentam de forma submissa.

Em relação à primeira periferia, cujos elementos estão presentes no quadrante superior direito do grupo feminino, é possível considerar uma dimensão afetiva onde, em primeiro lugar, está 0 amor, seguido pelo respeito, enquanto no masculino se nota a importância do amor, porém sem dissociálo da responsabilidade e do prazer, que os homens tanto almejam.

Os elementos de contraste, localizados no quadrante inferior esquerdo, têm um caráter mais voltado ao biológico, diferindo o grupo feminino, pela ocorrência de elementos como: opção, tempo certo e transar, levando a crer que as mulheres também dão significativa importância ao fenômeno, mas com certa maturidade, que se reflete na escolha do parceiro e a escolha do tempo que considera ser a hora certa de começar.

Ao se observar os elementos periféricos de ambos os sexos, ainda que estes termos estejam um pouco menos fixados na representação dos sujeitos estudados, logo notamos que a sexualidade para o universo feminino ainda tem um valor de amadurecimento. Em relação à convergência de ideias, ficou evidente a atenção destes indivíduos quanto a questões como filhos e doenças. Como mostram os resultados, estes termos ficaram distantes do núcleo central, reforçando a ideia da sua maior mutabilidade e instabilidade na representação. 0 léxico doença, em associação à palavra filhos, indica uma dimensão das consequências do ato sexual, podendo ser vistos como aspectos negativos que aparecem na periferia

Um dos temas mais recorrentes quando se discute a juventude, e em particular a sexualidade nesta fase, é a gravidez juvenil. A gravidez na adolescência é aquela que envolve a população até 19 anos..$^{15}$ Outro estudo expõe que mais da metade dos jovens do sexo masculino iniciaram-se sexualmente na faixa dos 10 aos 14 anos. As jovens, em sua maioria, têm sua primeira relação sexual entre os 15 e 19 anos de idade. Um dos pontos que normalmente se discute em relação à prevenção da gravidez é quanto ao grau de conhecimento dos métodos de contracepção. ${ }^{2}$ Acredita-se que os jovens tenham um nível de informação significativo sobre os métodos contraceptivos principais, no entanto o seu uso representa um assunto à parte, que não pode ser inferido do conhecimento existente.

Sabe-se que hoje a gravidez na adolescência tornou-se um problema de saúde pública no Brasil e em muitos outros países do mundo. Vários fatores etiológicos estão relacionados com o aumento do número de gestações entre jovens, e é preciso entendê-los e perceber sua complexidade e multicasualidade, para que seja possível intervir com mais eficácia, a fim de reduzir os índices que envolvem tal problemática. ${ }^{16}$

Os jovens, e possivelmente não apenas eles, ainda têm muita dificuldade para negociar o uso da camisinha com seus parceiros, por insegurança, medo de rejeição e desinformação, principalmente as mulheres que têm relações estáveis ou são casadas. Provavelmente o não uso do preservativo está relacionado, em muitos casos, à proximidade e intimidade que a pessoa tem com o parceiro. Alguns motivos associados a esse comportamento são: a falta de camisinha no momento do ato sexual; transar apenas com uma pessoa em quem confia; não gostar do preservativo porque diminui o prazer; e não achar que corre o risco de contrair AIDS.

Destaca-se que a representação social dos grupos estudados sobre a sexualidade é positiva e está relacionada a atitudes de prevenção e valorização da atividade sexual. A aproximação visivel entre sexualidade e práticas sexuais sugere que o conceito mais amplo ainda não foi incorporado por estes sujeitos.

As relações de gênero, tão marcantes na sociedade, podem ser identificadas nas representações destes jovens, uma vez que para as adolescentes do sexo feminino a representação da sexualidade está relacionada com uma dimensão de prevenção, enquanto que os adolescentes do sexo masculino, além de associar a sexualidade com a prevenção, têm uma representaçãa relacionada com uma dimensão imagética, ligada ao ato sexual.

\section{CONCLUSÃO}

A descoberta da sexualidade é vivenciada cada vez mais precocemente pelos adolescentes, o que tende a torná-los vulneráveis a determinadas doenças e causar conflitos pessoais e emocionais. Outros fatores, próprios desta faixa etária, contribuem para a exposição destes jovens como, por exemplo, a necessidade de pertencer ao grupo, o pensamento mágico e a sensação de invulnerabilidade.

Uma das principais características encontrada dentre os jovens estudados foi a for te importância que o transar possui em seu dia-a-dia, estando esta representação localizada no núcleo central, junto com outros termos também relevantes, que denotam a autonomia sexual como uma mudança cultural e comportamental por meio do sexo seguro, utilizando o preservativo masculino, principal método conhecido e aceito por eles. 
A partir destes vocábulos, pôde-se associar essa representação a uma dimensão com forte característica de segurança atrelada ao prazer. Pode-se, então, sugerir que o adolescente, ao estar protegido com alguma espécie de preservativo, fica mais tranquilo para realizar o ato sexual sem se preocupar com suas possíveis consequências, fazendo com que este seja bom, ou até mesmo maravilhoso, como foi referido pelos sujeitos.

Outro importante aspecto a ser destacado foi a presença de termos mais voltados ao prazer e ao ato sexual propriamente dito próximo ao núcleo central do grupo masculino. Estes resultados apontam que ainda prevalece a cultura de uma sociedade baseada no homem e na sua afirmação, com características peculiares a ele. Em contrapartida, as evocações do sexo feminino impressionam com a presença da palavra "prazer" já no núcleo central e com elevada frequência. Este resultado é de suma importância, pois demonstra uma grande mudanç̧a na maneira de pensar e colocar-se frente a uma cultura ainda resistente ao fortalecimento do papel feminino. Desta maneira, as mulheres buscam crescimento, afirmação e

\section{REFERÊNCIAS}

1. Melo ASAF, Santana JSS. Sexualidade: concepções, valores e condutas entre universitários de biologia da UEFS. Rev Baiana Saude Publ 2005 jul; 29(2): 149-59.

2. Castro MG, Abramovay M, Silva LB. Juventudes e sexualidade. Brasilia (DF): UNESCO; 2004.

3. Moscovici S. La psychanalyse, son image et son public. Paris(FR): P.U.F; 1961

4. Sá CP. Núcleo central das representações sociais. Petrópolis (RJ): Vozes; 1996

5. Sá CP. Núcleo central das representações sociais. $2^{\mathrm{a}}$ ed. Petrópolis (RJ): Vozes; 2002

6. Abric JC. 0 estudo experimental das representações sociais. In: Jodelet $\mathrm{D}$, organizadora. As representações sociais. Rio de Janeiro (RJ): UERJ; 2001. p. 155-72

7. Abric JC. A abordagem estrutural das representações sociais. In: Moreira ASP, Oliveira DC, organizadores. Estudos interdisciplinares em representação social. $2^{a}$ ed. Goiânia (GO): AB Ed; 2000. p.27-8.

8. Thompson ED, Ashwill JW. Uma introdução à enfermagem pediátrica. $6^{\text {a }}$ ed. Porto Alegre (RS): Artes Médicas; 1996.

9. Oliveira DC. A promoção da saúde da criança: análise das práticas cotidianas através do estudo das representaç̃̃es sociais [tese de doutorado]. São Paulo (SP): Faculdade de Saúde Pública /USP; 1996. demonstram simultaneamente a necessidade de satisfação pessoal em um amplo aspecto.

Apesar desta grande mudança, isto não exclui a característica que é mais marcante e originalmente pertencente a este grupo, a presença da afetividade e do respeito como partícipes da representação e buscados nos relacionamentos interpessoais.

A sexualidade se destaca como campo em que a busca por autonomia de projetos e práticas é exercida de forma única e com a urgência característica dos jovens. Dessa maneira, as trajetórias de vida são marcadas por exigências quanto ao desempenho e as afirmações sobre o eu no mundo, caracterizando-se, entre outras dimensões, por tênues fronteiras entre a intimidade, formas de ser, padrões socioculturais e por ditames da sociedade de consumo ${ }^{17}$.

Conclui-se que as representações estão ligadas a comportamentos adotados diante da sexualidade e da sua valorização, bem como da existência de dimensões transversais às diversas estruturas. Observa-se a importância de desenvolvimento de atividades educativas pelos enfermeiros, de modo que os jovens consigam vivenciar esta dimensão humana com qualidade e segurança.

10. Oliveira DC. A enfermagem e as necessidades humanas básicas: o saber/fazer a partir das representações sociais [tese de professor titular]. Rio de Janeiro (RJ): Faculdade de Enfermagem/UERJ; 2001.

11. Monteiro S. AIDS, sexualidade e gênero: a lógica da proteção entre jovens de um bairro popular carioca [tese de doutorado]. Rio de Janeiro (RJ): Fiocruz; 1999.

12. Taquette SR, Andrade RB de, Vilhena MM, Paula MC de. A relação entre as características sociais e comportamentais da adolescente e as doenças sexualmente transmissíveis. Rev Assoc Médica Bras 2005; 51 (3): 148-52.

13. Egypto MM. Papéis sexuais. In: Barroso C, Brushini C, organizadores. Sexo e juventude: como discutir sexualidade em casa e na escola. $5^{\text {a }}$ ed. São Paulo (SP): Cortez; 1995.

14. Benite AM. A percepção de estudantes adolescentes sobre sexualidade: uma análise de representações sociais [dissertação de mestrado]. Rio de Janeiro (RJ): Faculdade de Enfermagem/UERJ; 2004.

15. Sexual relations among young people in developing countries: evidences from WHO case studies. Genebra: WHO; 2001.

16. Arcanjo CM, Oliveira MIV, Bezerra MGA. Gravidez em adolescentes de uma unidade municipal de saúde em Fortaleza - Ceará. Esc Anna Nery Rev Enferm 2007. set; 11(3): 445 - 51.

17. Giddens A. A transformação da identidade: sexo, amor e erotismo nas sociedades modernas. São Paulo (SP): UNESP; 1993 